\title{
Choosing the decolourizer and its strength to stain Mycobacterium leprae. Does it actually matter?
}

\author{
R. DE SOLDENHOFF, M. HATTA \& \\ T. WELING SIRO* \\ NSL-South Sulawesi Leprosy Control Project; Provincial Health \\ Services, South Sulawesi, Indonesia; \\ *Department of Microbiology, Medical Faculty of Hasanuddin \\ University, Ujung Pandang, Indonesia
}

Accepted for publication 15 April 1998

\begin{abstract}
Summary Leprosy bacilli are more easily decolourized during staining than tuberculosis bacilli, so a weaker concentration of decolourizer is usually recommended. In Indonesia, the same 'strong' decolourizer is used for identifying both organisms. In a study to compare the results using different concentrations of different decolourizers, no difference could be found in the bacterial index (BI). It is suggested that the same staining technique can be used for tuberculosis and leprosy.
\end{abstract}

\section{Introduction}

Ideally, all leprosy patients should have one skin smear examination before starting treatment, if reliable facilities are available. ${ }^{1}$ The Ziehl-Neelsen method involves staining with carbol fuchsin, followed by decolourization then counterstaining with methylene blue. ${ }^{2}$ If the decolourization process is excessive, bacilli may be rendered invisible. Concerns regarding which decolourizer to use, what strength and for how long, have resulted in several investigations. ${ }^{3-6}$

In Indonesia, the same staining technique is normally used for leprosy and tuberculosis, despite the widely accepted opinion regarding the reduced acid and alcohol 'fastness' of Mycobacterium leprae. ${ }^{2}$ The objective of this study was again to find out if (i) different decolourizers and (ii) different concentrations of the same decolourizer had an effect on the BI of skin smears.

Although the Ziehl-Neelsen stain is used universally to stain $M$. leprae, there are many modifications. ${ }^{7}$ The main difference between the technique for leprosy and tuberculosis is the strength of the decolourizer, but in addition, the duration of decolourizing varies. For tuberculosis, this is usually either $25 \%$ sulphuric acid or $3 \%$ hydrochloric acid in $70 \%$

Correspondence to: NSL-Sulsel Leprosy Control Project, PO Box 1011, Ujung Pandang, Sulawesi, Indonesia. e-mail: richards@upg.mega.net.id 
ethanol for 3 min. $^{8}$ For leprosy, decolourization or differentiation using $1 \%$ hydrochloric acid in $70 \%$ ethanol is favoured by most, ${ }^{2,7,9,10}$ but $5 \%$ sulphuric acid by some. ${ }^{11}$ Dharmendra surprisingly recommends $3 \%$ acid alcohol. ${ }^{12}$ The counterstain is usually methylene blue, although the concentration varies between $0 \cdot 2 \%{ }^{11}$ and $1 \% .^{6}$ Vettom and Pritze found 10 different techniques from 29 projects, the most notable variations being in decolourization time. ${ }^{13}$ They ranged from $1 \%$ acid alcohol for $5 \mathrm{~s}$ to $20 \%$ acid alcohol for $1 \mathrm{~min}$ and from $5 \%$ sulphuric acid for 1 min to $25 \%$ sulphuric acid for $10-20$ min. $^{13}$

Despite this, several research laboratories use the same concentration of decolourizer for leprosy as for tuberculosis (A. McDougall, personal communication). The Indonesian leprosy manual describes two possible Ziehl-Neelsen methods, one with acid alcohol (concentration not specified) for $3-5 \mathrm{~s}$ and the other with $25 \%$ sulphuric acid for $8 \mathrm{~s} .{ }^{14}$

\section{Materials and methods}

Skin smears were taken from 40 multibacillary (MB) leprosy patients, with a range of BI. The selection was by the technician who took the smears, did the staining and read the results. The patients were registered cases and were on WHO MB multidrug therapy (MDT). ${ }^{1}$ All patients had smears taken from four standard sites with four identical slides being made from each patient, each slide with the four sites on it.

Apart from the decolourizer, the same Ziehl-Neelsen method was used. ${ }^{15}$ The decolourizers were $1 \%$ hydrochloric acid in $70 \%$ ethyl alcohol $(\mathrm{HCl}), 3 \%$ hydrochloric acid in $70 \%$ ethyl alcohol, 5\% sulphuric acid $\left(\mathrm{H}_{2} \mathrm{SO}_{4}\right)$ and $25 \%$ sulphuric acid. Slides were stained in batches. Carbol fuchsin was filtered onto the slide, allowed to act for $2 \mathrm{~min}$, heated gently until steam rose, allowed to act for a further $10 \mathrm{~min}$, washed with tap water until clean, transferred to a staining rack and dipped in decolourizer for $8 \mathrm{~s}$. If any slide was still red, this was repeated, washed, and counterstained with $0.3 \%$ methylene blue for $1 \mathrm{~min}$. Most slides only received one immersion in the decolourizer.

The intention was that the examination of the smears would be blind, but it was possible to distinguish immediately between the slides decolourized with $\mathrm{HCl}$ and those with $\mathrm{H}_{2} \mathrm{SO}_{4}$, by microscopy of the smear. It was not possible to distinguish between $1 \%$ and $3 \% \mathrm{HCl}$ or between $5 \%$ and $25 \% \mathrm{H}_{2} \mathrm{SO}_{4}$.

The BI was reported for each of the four smears on the slide and the average was calculated. The morphological index (MI) is not routinely used in Indonesia.

The results were compared using the Student's paired $t$-test. ${ }^{16}$ Differences were considered significant at the $95 \%$ level of confidence.

\section{Results}

Forty patients had slit skin smears taken, resulting in 160 slides. Each slide had four smears, except in the case of patient 6, who fainted after smears had been taken from two sites (ears). Thirty-four patients were positive with at least one staining technique. An average BI was calculated for each of the 160 slides (see Table 1). Comparison was also made using individual smears.

Eleven patients had a higher $\mathrm{BI}$ with $1 \% \mathrm{HCl}$ than with $3 \%$. Twelve patients had a lower BI with $1 \% \mathrm{HCl}$ than with $3 \%$. Eight patients had a higher $\mathrm{BI}$ with $5 \% \mathrm{H}_{2} \mathrm{SO}_{4}$ than with $25 \%$. Thirteen patients had a lower BI with $5 \% \mathrm{H}_{2} \mathrm{SO}_{4}$ than with $25 \%$. 
When looking at low BIs (i.e. $>0$ but $<2$ ), the same pattern was observed. Eleven patients had a low $\mathrm{BI}$ using $1 \% \mathrm{HCl}$. In two cases, the $\mathrm{BI}$ was greater using $1 \%$, and in five cases, the BI was less. Twelve patients had a low BI using $5 \% \mathrm{H}_{2} \mathrm{SO}_{4}$. In three cases, the BI was greater using $5 \%$ and in five cases, the $\mathrm{BI}$ was lower with $5 \%$.

Table 1. BI results for 40 patients using four decolourizers

\begin{tabular}{|c|c|c|c|c|c|c|c|}
\hline Patient & $\begin{array}{l}1 \% \text { acid } \\
\text { alcohol }\end{array}$ & $\begin{array}{l}3 \% \text { acid } \\
\text { alcohol }\end{array}$ & Difference & $\begin{array}{l}5 \% \text { sulphuric } \\
\text { acid }\end{array}$ & $\begin{array}{l}25 \% \text { sulphuric } \\
\text { acid }\end{array}$ & Difference & $\begin{array}{l}\text { Difference between } \\
1 \% \text { HCI \& } 5 \% \\
\text { sulphuric acid }\end{array}$ \\
\hline 1 & $1 \cdot 75$ & $2 \cdot 25$ & -0.5 & 2 & $1 \cdot 75$ & $0 \cdot 25$ & $-0 \cdot 25$ \\
\hline 2 & 1 & 1 & 0 & 0.75 & $0 \cdot 75$ & 0 & $0 \cdot 25$ \\
\hline 3 & $4 \cdot 75$ & $4 \cdot 5$ & $0 \cdot 25$ & 4 & $4 \cdot 25$ & $-0 \cdot 25$ & $0 \cdot 75$ \\
\hline 4 & 1 & 1 & 0 & 1 & $0 \cdot 75$ & $0 \cdot 25$ & 0 \\
\hline 5 & 0 & 0 & 0 & 0 & 0 & 0 & 0 \\
\hline 6 & 4 & 4 & 0 & 3 & 4 & 1 & 1 \\
\hline 7 & 2 & $1 \cdot 75$ & $0 \cdot 25$ & 1 & $1 \cdot 25$ & $-0 \cdot 25$ & 1 \\
\hline 8 & $3 \cdot 75$ & $3 \cdot 5$ & $0 \cdot 25$ & 4 & 4 & 0 & $-0 \cdot 25$ \\
\hline 9 & $4 \cdot 5$ & $3 \cdot 75$ & 0.75 & 4 & $4 \cdot 25$ & $-0 \cdot 25$ & $0 \cdot 5$ \\
\hline 10 & $1 \cdot 5$ & $1 \cdot 75$ & $-0 \cdot 25$ & $1 \cdot 25$ & $1 \cdot 25$ & 0 & $0 \cdot 25$ \\
\hline 11 & $2 \cdot 75$ & $2 \cdot 5$ & $0 \cdot 25$ & $1 \cdot 75$ & $2 \cdot 75$ & -1 & 1 \\
\hline 12 & $0 \cdot 5$ & $1 \cdot 5$ & -1 & $0 \cdot 5$ & 0 & $0 \cdot 5$ & 0 \\
\hline 13 & 1 & $1 \cdot 75$ & $-0 \cdot 75$ & $1 \cdot 25$ & $1 \cdot 25$ & 0 & $-0 \cdot 25$ \\
\hline 14 & 0 & 0 & 0 & 0 & 0 & 0 & 0 \\
\hline 15 & $4 \cdot 5$ & 4 & $0 \cdot 5$ & 0 & $3 \cdot 25$ & $-3 \cdot 25$ & $4 \cdot 5$ \\
\hline 16 & $1 \cdot 75$ & $2 \cdot 75$ & -1 & 0 & $3 \cdot 25$ & $-3 \cdot 25$ & $1 \cdot 75$ \\
\hline 17 & $2 \cdot 5$ & $2 \cdot 75$ & $-0 \cdot 25$ & 0 & $2 \cdot 5$ & $-2 \cdot 5$ & $2 \cdot 5$ \\
\hline 18 & $1 \cdot 25$ & 1 & $0 \cdot 25$ & 1 & 1 & 0 & $0 \cdot 25$ \\
\hline 19 & 0 & 0 & 0 & 0 & 0 & 0 & 0 \\
\hline 20 & $4 \cdot 25$ & $4 \cdot 25$ & 0 & $4 \cdot 25$ & $3 \cdot 5$ & 0.75 & 0 \\
\hline 21 & $2 \cdot 75$ & $2 \cdot 25$ & $0 \cdot 5$ & $1 \cdot 5$ & $3 \cdot 5$ & -2 & $1 \cdot 25$ \\
\hline 22 & $0 \cdot 5$ & $0 \cdot 5$ & 0 & $0 \cdot 25$ & 0 & $0 \cdot 25$ & $0 \cdot 25$ \\
\hline 23 & 0 & 0 & 0 & 0 & 0 & 0 & 0 \\
\hline 24 & $4 \cdot 75$ & $4 \cdot 75$ & 0 & $4 \cdot 5$ & 4 & 0.5 & $0 \cdot 25$ \\
\hline 25 & 0 & 0 & 0 & 0 & 0 & 0 & 0 \\
\hline 26 & $3 \cdot 25$ & 4 & $-0 \cdot 75$ & 3 & $3 \cdot 25$ & $-0 \cdot 25$ & $0 \cdot 25$ \\
\hline 27 & 2 & $2 \cdot 25$ & $-0 \cdot 25$ & 0 & 0 & 0 & 2 \\
\hline 28 & $3 \cdot 75$ & $3 \cdot 75$ & 0 & $3 \cdot 75$ & $3 \cdot 75$ & 0 & 0 \\
\hline 29 & $4 \cdot 75$ & $4 \cdot 75$ & 0 & $4 \cdot 5$ & $4 \cdot 5$ & 0 & $0 \cdot 25$ \\
\hline 30 & $3 \cdot 5$ & $3 \cdot 75$ & $-0 \cdot 25$ & $3 \cdot 5$ & $2 \cdot 25$ & $1 \cdot 25$ & 0 \\
\hline 31 & $3 \cdot 5$ & 4 & -0.5 & 3 & $2 \cdot 5$ & $0 \cdot 5$ & 0.5 \\
\hline 32 & 4 & $3 \cdot 75$ & $0 \cdot 25$ & $4 \cdot 25$ & $4 \cdot 25$ & 0 & $-0 \cdot 25$ \\
\hline 33 & 5 & 5 & 0 & 5 & 5 & 0 & 0 \\
\hline 34 & $1 \cdot 25$ & $0 \cdot 5$ & $0 \cdot 75$ & $0 \cdot 25$ & $0 \cdot 75$ & $-0 \cdot 5$ & 1 \\
\hline 35 & 0 & 0 & 0 & 0 & 0 & 0 & 0 \\
\hline 36 & $3 \cdot 5$ & $4 \cdot 25$ & -0.75 & $3 \cdot 75$ & $3 \cdot 75$ & 0 & $-0 \cdot 25$ \\
\hline 37 & 2 & $3 \cdot 5$ & $-1 \cdot 5$ & $3 \cdot 75$ & $3 \cdot 75$ & 0 & $-1 \cdot 75$ \\
\hline 38 & 0 & $1 \cdot 25$ & $-1 \cdot 25$ & $0 \cdot 75$ & $1 \cdot 25$ & -0.5 & -0.75 \\
\hline 39 & 0.5 & $0 \cdot 5$ & 0 & 0 & $1 \cdot 25$ & $-1 \cdot 25$ & $0 \cdot 5$ \\
\hline 40 & $4 \cdot 75$ & $4 \cdot 25$ & 0.5 & $4 \cdot 75$ & $4 \cdot 75$ & 0 & 0 \\
\hline Total & $92 \cdot 5$ & 97 & $-4 \cdot 5$ & $76 \cdot 25$ & $88 \cdot 25$ & -12 & $16 \cdot 25$ \\
\hline Average & $2 \cdot 31$ & $2 \cdot 43$ & $(0 \cdot 11)$ & 1.91 & $2 \cdot 21$ & $(0 \cdot 30)$ & $0 \cdot 41$ \\
\hline SD & & & 0.50 & & & 0.94 & 0.98 \\
\hline$p$ value & & & $<0 \cdot 2$ & & & $<0 \cdot 1$ & $<0.02$ \\
\hline
\end{tabular}


The average of all the $\mathrm{BIs}$ using $1 \% \mathrm{HCl}$ was $2 \cdot 31$ (with seven negatives). The average $\mathrm{BI}$ using $3 \% \mathrm{HCl}$ was $2 \cdot 43$ (with six negatives). The difference between the BIs was not statistically significant $(p<0 \cdot 2$ and $>0 \cdot 1)$. The average $\mathrm{BI}$ using $5 \% \mathrm{H}_{2} \mathrm{SO}_{4}$ was 1.91 (with 11 negatives). The average $\mathrm{BI}$ using $25 \% \mathrm{H}_{2} \mathrm{SO}_{4}$ was $2 \cdot 21$ (with nine negatives). Again, the difference between the BIs is not statistically significant $(p<0 \cdot 1$ and $>0.05)$. When the differences between the BIs with $1 \%$ acid alcohol and $5 \%$ sulphuric acid were examined, there was an average fall of $0 \cdot 41$. This was significant at the $2 \%$ level $(p<0.02)$, suggesting that there might be a real decrease in BI when using sulphuric acid.

There was generally good correlation between the four slide results from each patient. An exception was found in patients 15,16 and 17 , where the slides stained with $5 \% \mathrm{H}_{2} \mathrm{SO}_{4}$ were negative, whereas the other three were moderately or strongly positive. The most likely explanation for this was that these slides were wiped clean on the wrong side of the slide, hence removing all four smears from the slide. If the results from these three patients are excluded, the average BIs are 2.26 and 2.36 for acid alcohol and 2.06 and 2.14 for sulphuric acid. The differences between these figures (between the two acid alcohols, the two sulphuric acids and between $1 \%$ acid alcohol and 5\% sulphuric acid) all fail to reach statistical significance $(p<0.5, p<0.5$ and $p<0 \cdot 1$, respectively).

In 38 of 158 sites examined, there was a variation of two or more BI units (i.e. more than a 10 -fold difference in the number of bacilli) from the same site using different decolourizers. No pattern was observed.

The slides which were stained using an acid alcohol decolourizer were generally easier to examine than those using sulphuric acid. Irrespective of concentration, the bacilli were sharper, clearer, more red, the background had accepted more blue for differentiation and there was little or none of the background pink 'fuzz' that is a feature of the slides which were decolourized using $5 \%$ or $25 \% \mathrm{H}_{2} \mathrm{SO}_{4}$.

\section{Discussion}

\section{POSITIVITY}

This study failed to show that a stronger decolourizer resulted in a lower BI. The BI was slightly higher with the stronger concentration, but not reaching statistical significance (see Figure 1). This was also noted when looking at the results from patients with a low $(<2) \mathrm{BI}$. The BI was slightly lower with sulphuric acid, this reaching significance only when the questionable data from patients 15,16 and 17 were included.

POSSIBLE BIAS

All patients were purposefully selected. No attempt was made to have a representative sample of leprosy patients, new or otherwise. Since the purpose of the study was to compare results patient by patient, analysis using an average BI for all patients per technique is open to question. The difference in BI from the same site could also be affected by the quality of the smear and within-observer variation. Three patients had results which suggest a major laboratory error. Analysis was also performed excluding results from these three patients.

DOES IT REALLY MATTER?

Most new leprosy patients can be competently diagnosed and commenced on appropriate 


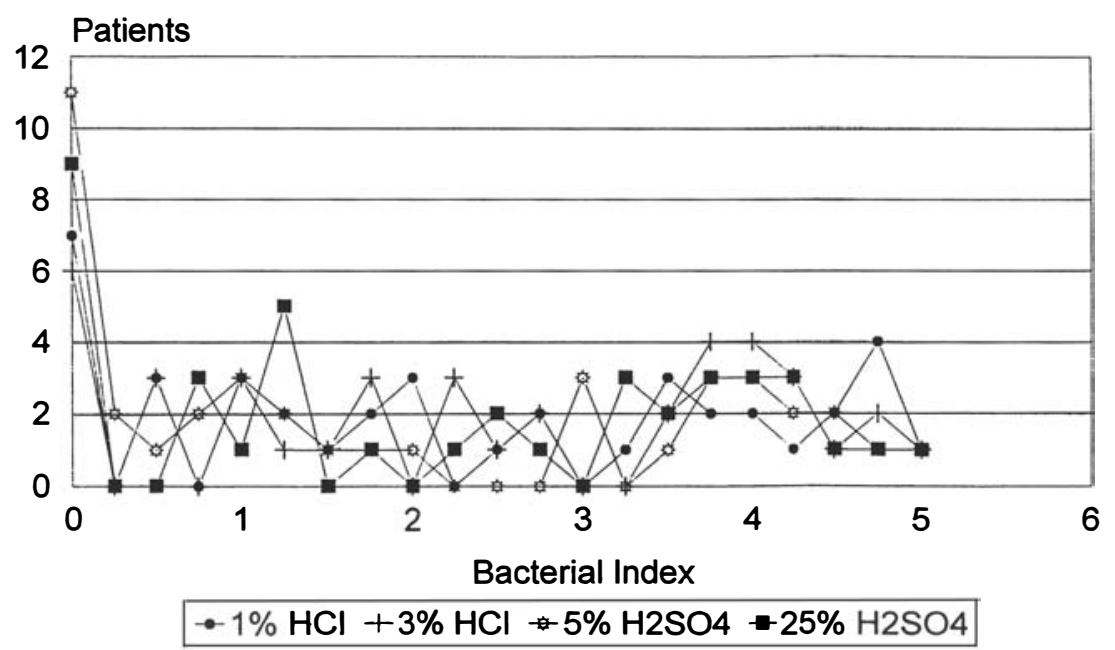

Figure 1. Comparison of BI results using four decolourizers.

treatment without a skin smear. However, there are some patients who present with single or few lesions, but who have early multibacillary disease. ${ }^{17}$ There are other patients, either new or old, who have no clearly demonstrable clinical cardinal signs, but who have a positive smear. There are suspicions that some multibacillary patients, who are released from fixed duration treatment but still with a BI of $>3$, may have a significant relapse rate. It has been suggested that regular clinical and bacteriological review after release from treatment is indicated for these patients. ${ }^{18}$ Where communications are difficult, it may not be practical to refer all smear examinations to a referral laboratory. ${ }^{19}$ Hence, there is still be a need for skin smear examination to be made available, at least at district level.

The success of the WHO Elimination Strategy suggests that there will gradually be fewer positive smears. Leprosy will not, however, be eradicated by the year 2000. It is therefore essential that there be accessible centres with trained staff who will be able to carry out this procedure accurately. As the world tuberculosis situation deteriorates, it becomes increasingly necessary to have laboratories in peripheral health units capable of bacteriological examination of sputum. Tuberculosis diagnosing centres (possibly one such laboratory per 100,000 of the population ${ }^{20}$ ), with an established system of quality control, can also be responsible for leprosy microscopy. This is easier if the staining technique for both organisms is identical. From this study, it does not appear likely that the choice of decolourizer or its strength is a major factor in the general unreliability of skin smear services in some parts of the world.

It is possible that this is a much more robust technology than is generally thought. This study suggests that the same technique for staining leprosy and tuberculosis bacilli can be used, furthermore, that acid alcohol is an improvement on sulphuric acid.

\section{Acknowledgements}

We thank Dr A. Colin McDougall of Oxford, UK, for his advice and encouragement. We also 
thank the leprosy patients and staff of the B.P. Kulit Skin Clinic and R.S. Daya Leprosy Hospital, for their assistance. The leprosy control programme of the Indonesian Ministry of Health in South Sulawesi is supported by the Netherlands Leprosy Relief Association (NSL).

\section{References}

1 WHO. A guide to eliminating leprosy as a public health problem. WHO/LEP/95.1, 1st Edn, 1995.

2 Leiker DL, McDougall AC. Technical guide for smear examination for leprosy, 2 nd revised edition. Talmilep, Wurzburg, 1987.

3 Davidson AR. Decolorizing of Mycobacterium leprae. Int J Lepr, 1943; 2: 49-51.

4 Davidson AR. The technique of staining leprosy bacilli in smears. Lepr Rev, 1960; 31: 305-307.

5 Padma MN. A standard technique of acid fast staining for M. leprae in smears. Lepr India. 1963; 35: 62-64.

${ }^{6}$ Ridley MJ \& Ridley DS. Stain techniques and the morphology of M. leprae. Lepr Rev, 1971; 42: 88-95.

7 Ridley MJ. The cellular exudate-Mycobacterium leprae relationship and the critical reading of skin smears. Lepr Rev, 1989; 60: 229-240.

8 International Union Against Tuberculosis and Lung Diseases (IUATLD). Technical Guide For Sputum Examination For Tuberculosis By Direct Microscopy, 1978. In: Tuberculosis guide for low income countries, 4th edn. IUATLD, Paris; 1996.

9 WHO. Laboratory techniques for leprosy. WHO/CDS/LEP/86.4, 1987.

${ }^{10}$ Nilsen T, Sparell G. Skin smears for leprosy. ALERT, Addis Ababa, DAHW/Talmilep, 1990.

11 SLR\&TC. Skin smear examination. Technical Manual Sr. No. 3.1, Schieffelin Leprosy Rehabilitation and Training Centre, Karigiri, India, 1987.

12 Dharmendra (ed). Leprosy, Vol. 1. Kothari Medical Publ. House, Bombay, 1978.

13 Vettom L, Pritze S. Reliability of skin smear results: experiences with quality control of skin smears in different routine services in leprosy control programmes. Lepr Rev, 1989; 60: 187-196.

14 Buku Pedoman Pemberantasan Penyakit Kusta (Manual for workers in the leprosy programme). Edn. IX, Department of Health, Jakarta, 1995.

15 Petunjuk Teknis Penatalaksanaan Laboratorium Di Puskesmas (Technical guidelines for health centre laboratory procedures). Department of Health, Jakarta, 1990.

16 Kirkwood BR. Essentials of medical statistics. Blackwell Scientific Publications, Oxford, 1992.

17 Ponnighaus JM. Diagnosis and management of single lesion leprosy. Lepr Rev, 1996; 67: 89-94.

18 Desikan KV. The risk of relapse after multidrug therapy in leprosy. Lepr Rev, 1997; 68: 114-116.

${ }^{19}$ Georgiev GD, McDougall AC. Skin smears and the bacterial index (BI) in multiple drug therapy leprosy control programmes: an unsatisfactory and potentially hazardous state of affairs. Int J Lepr, 1988; 56: 101-103.

20 International Union Against Tuberculosis and Lung Diseases (IUATLD). Tuberculosis guide for low income countries, 4th edn. IUATLD, Paris, 1996. 